\title{
IMIA: Coalescing Medical Informatics Worldwide for 40 Years
}

\author{
C. A. Kulikowski \\ Department of Computer Science, Rutgers University, New Brunswick, USA
}

\begin{abstract}
Summary
Objectives: To summarize and highlight the role of IMIA in the past 40 years in becoming the international professional organization that brings together researchers, practitioners, and educators in the field of medical informatics, and more broadly biomedical, nursing, and health informatics

Method: Outlining developments of medical informatics related to IMIA from 1967 to 2007 in a time-line and comparative topic and geographical distribution analyses over selected MEDINFOs from 1980 and selected Yearbooks from 1992 onwards. This illustrates how IMIA, through the global reach of its activities, has helped advance the science and development of informatics across the entire spectrum of biomedical and health care research, education, and practice.

Results and conclusions: The contribution of IMIA over the past 40 years has been to sponsor and coordinate international conferences and promote interchange and collaborations in biomedical and health informatics by linking national and regional societies, organizing meetings, high quality publications, and working groups. These have helped the coalescing of the discipline worldwide, promoting full participation and a broad interdisciplinary scope that fulfills the hopes of the pioneers in the field.
\end{abstract}

\section{Keywords}

International Medical Informatics Association (IMIA) history, medical informatics, health and nursing informatics, world congresses of medical informatics (MEDINFOS), IMIA Yearbook, and Working Groups

Geissbuhler A, Haux R, Kulikowski C, editors. IMIA Yearbook of Medical Informatics 2007. Methods Inf Med 2007; 46 Suppl I: 176-85

\section{Introduction}

IMIA has been the catalyst for international coordination and collaboration among medical informatics (MI) researchers and practitioners since its inception. Its origins can be traced to 1967, when François Grémy organized and became the first moderator of the Technical Committee for Medical Information Processing (TC-4) within the International Federation of Information Processing (IFIP) Societies [1]. An international congress on medical informatics had been held in 1966 in Elsinore, bringing together many of the pioneers in MI from the USA, France, the UK, the Netherlands, Italy, Germany, Poland, Japan, Puerto Rico, Norway, Sweden, and Denmark [2]. This helped raise consciousness of the wide geographical scope of interest in the field. Earlier, in 1962, Gustav Wagner had started what would become the first official journal of IMIA: Methods of Information in Medicine, initially in German, and later in English [3].

IMIA itself gradually emerged as an association of national and regional societies in MI over the next two decades.It became a separate organization reporting to IFIP in 1979, independent of IFIP in 1988, and then established legally under Swiss law between 1989 and 1992 [4]. Today IMIA is an independent, international professional organization which sponsors research, practice, and education through a wide range of international working groups (WGs) on MI topics with a very broad impact, hav- ing extended gradually to nursing, public health, and bioinformatics. By sponsoring triennial World Congresses of Medical Informatics (better known by their MEDINFO [5] acronym) and an annual IMIA Yearbook of Medical Informatics [6], as well as many WG publications, and professional journals, IMIA provides a forum for highlighting the most comprehensive range of international research and education activities in its field. As stated on its website:

"The goals and objectives of IMIA are: - the promotion of informatics in health care and biomedical research

- the advancement of international cooperation

- the stimulation of research, development and education

- the dissemination and exchange of information

Inherent in this mission is to bring together, from a global perspective, scientists, researchers, vendors, consultants and suppliers in an environment of cooperation and sharing. The international membership network of $\mathrm{Na}$ tional Member Societies, IMIA Regions, Corporate and Academic Institutional Members, and the Working and Special Interest Groups that constitute the "IMIA family" is uniquely positioned to achieve these goals [7].

"Thus, IMIA provides a focus for the profession, covering the range of MI (and more broadly biomedical, nursing and health informatics), helping define and coalesce the field through international perspectives on how the underlying sciences and technologies of information and knowledge impact the 
many intersections of health care, biomedical research and education.

The international dimensions of IMIA are emphasized by the number of national societies and regional federations which it encompasses. The national societies can be either full (dues paying) members of IMIA or corresponding and provisional members during periods of organization or transition, respectively. IMIA allows only one national member society per country. The regional organizations are, by order of accession: EFMI (the European Federation for Medical Informatics) established in 1976, and comprising 27 member societies; IMIA-LAC Latin American Federation for Medical Informatics first organized in 1980 and re-organized in 1996, comprising four full member societies and one observer member; APAMI (Asia-Pacific Association for Medical Informatics) organized in 1993 with 13 members; and HELINA: African Region also established in 1993 comprising two full members and three corresponding members. North America is represented by $\mathrm{COACH}$ : Canada's Health Informatics Association, founded in 1975, and AMIA, the American Medical Informatics Association, founded in 1990 through the merger of three precursor medical informatics organizations in the USA. There are presently 49 national member societies, and 33 corresponding member countries, plus several more (provisional members) in the process of affiliation with IMIA. In addition, IMIA is affiliated with the World Health Organization (WHO), the federation of societies IFIP from which it emerged, and the International Federation of Health Records Organizations (IFHRO). IMIA also counts 61 institutional members -11 corporate and 50 academic - representing research, practice, and educational medical informatics institutions globally.

\section{Emergence of Medical Informatics}

With the breakneck speed of technological advances, wide range of applications, very diverse scientific backgrounds, and highly varied national and regional experiences in computing, informatics, and biomedicine over the past four decades, it is hardly surprising that biomedical informatics itself has evolved through many divergent and convergent paths as researchers, practitioners, and educators came up with idiosyncratic approaches to shared problems. It took some time for those involved to realize that there were advantages to be had in a shared discipline. A few pioneering researchers, health practitioners and educators as early as the 1950s found a deep common interest in the potential of computers and information technology to change the practice of medicine and biomedical research [1,8-10]. Initially this involved as much hardware as software innovation, but with the gradual ubiquity of mainframe systems and high-level languages, and the later development of personal computers, focus in medical informatics became more centered on software systems and fundamental models of information processing (especially data and knowledge representation and management), their computer systems implementation, and evaluation. Problems and developments in the hardware for measurements, sensor technologies, and signal and image processing gradually became predominantly more the domain of biomedical engineering or specialized scientific and technical subfields in informatics and related disciplines.

The term medical informatics came to be adopted gradually. It had its origins in France in the early 1970s, and spread around the world during the decade, though it took till the 1980s for it to be adopted in the USA. Meanwhile the various strands of biomedical computation began to cover health care more broadly, with strong emphases on the informatics of library and information organization, and instrument and systems applications in healthcare, including nursing and dental practice.

So, from its beginnings, biomedical, health, and nursing informatics have enjoyed an incredible breadth of participation by researchers and practitioners from many disciplines: medicine and dentistry, mathematics (including statistics), physics, chemistry, engineering, nursing, public health, biology, computer science (when it coalesced as a separate discipline in the 1960s), operations research, library and information sciences (when they likewise coalesced around the same time), and increasing numbers of sub-specializations and sub-disciplines of these.

\section{IMIA Timeline}

To give a single time-line of events, participants, and contributions would be a massive undertaking, and this $40^{\text {th }} \mathrm{An}$ niversary IMIA Yearbook for 2007 includes a paper by three of the Past Presidents of the organization, containing a wealth of personal insights and information, as well as Tables of the major conferences, presidents, and Yearbook topics [11]. The summary timeline below brings together material from the general chronicle from the IMIA website [1] based on Marian Ball's original notes, to which I have added a small selection of related medical informatics events, many drawn from Morris Collen's history of medical informatics [8] which, while focused on the USA, does cover many international developments - as well as from other references concentrating on the early days and precursors of medical informatics. 
Kulikowski

Table 1 Timeline Listing of Selected Precursor, Related, and IMIA Events

\begin{tabular}{|c|c|}
\hline Year & IMIA and selected Precursor and Related Medical Informatics Events \\
\hline 1950's & $\begin{array}{l}\text { Biomedical electronics and early analog and digital computing applications for medical records and biomedical research as precursors of medical informatics mainly in the USA and } \\
\text { Europe, together with precursor professional society involvement. }\end{array}$ \\
\hline 1959 & $\begin{array}{l}\text { Major precursor academic article on medical informatics by Ledley and Lusted (USA) published in Science: "Reasoning Foundations of Medical Diagnosis"[10]. First IBM Medical } \\
\text { Symposium indicating commercial interest in the field. }\end{array}$ \\
\hline 1960 's & $\begin{array}{l}\text { Articles on computer applications in biomedicine begin to proliferate, several books published, specialized scientific meetings sponsored by engineering and computing societies, } \\
\text { and regular funding of biomedical computing by government agencies. }\end{array}$ \\
\hline 1962 & Precursor of first IMIA journal Methods of Information in Medicine, founded by Gustav Wagner (Germany). \\
\hline 1964 & National Library of Medicine (NLM) in the USA begins to computerize Index Medicus and develop MEDLARS (Medical Literature Analysis and Retrieval System). \\
\hline 1966 & $\begin{array}{l}\text { Elsinore (Denmark) Congress on Medical Informatics brings many international participants in the future field of medical informatics together. } \\
\text { Society of Biomedical Computing founded in USA with Octo Barnett as first president. }\end{array}$ \\
\hline 1967 & $\begin{array}{l}\text { Precursor of IMIA, the International Federation of Information Processing (IFIP) TC-4 on Medical Information Processing established by François Grémy (France). } \\
\text { Journal Computers in Biomedical Research (Academic Press) edited by Homer Warner (USA). }\end{array}$ \\
\hline 1968 & Influential precursor volumes on medical informatics published: Donald Lindberg's The Computer and Medical Care [12] and Lee Lusted's Introduction to Medical Diagnosis[13]. \\
\hline 1970 & $\begin{array}{l}\text { Conference sponsored by IFIP TC-4: Anderson J Forsythe JM, eds. Information Processing of Medical Records [14]. } \\
\text { Vereniging (Society) for Medical and Biological Information Processing, founded in the Netherlands with Jan Roukens as first chairman }\end{array}$ \\
\hline 1971 & International Health Evaluation Association (IHEA) formed to support evaluation and computerization of health systems with emphasis on multiphasic screening. \\
\hline 1973 & $\begin{array}{l}\text { Conference sponsored by IFIP TC4: Zywietz C and Schneider B, eds. Computer Application on ECG and VCG Analysis [15] } \\
\text { Conference on education in medical informatics held in Reisenburg (Germany) [16] }\end{array}$ \\
\hline 1974 & $\begin{array}{l}\text { MEDINFO: First World Congress on Medical Informatics, Stockholm (Sweden) [17] in conjunction with IFIP World Congress. } \\
\text { IFIP Medical Informatics Monographs from IMIA conferences: Education in Informatics of Health Personne/ (Anderson J, Grémy F and Pages J, eds.) [18]; and Mathematical } \\
\text { Models in Biology and Medicine Bailey JJ, Isanev A, eds) [19] } \\
\text { Series of Lecture Notes on Medical Informaticsinitiated under editorship of Donald Lindberg, Peter Reichertz and Otto Rienhoff published by Springer-Verlag. Heidelberg and New York [20] }\end{array}$ \\
\hline 1975 & $\begin{array}{l}\text { Jan Roukens (the Netherlands) becomes TC-4 moderator. } \\
\text { Canada's Health Informatics Association (COACH) founded. }\end{array}$ \\
\hline 1976 & First regional society in medical informatics is founded: the European Federation of Medical Informatics (EFMI) \\
\hline 1977 & $\begin{array}{l}\text { Second MEDINFO held in Toronto, Canada [21] organized by IFIP-TC4's Werner Schneider (Sweden). } \\
\text { First Annual Symposium on Computer Applications in Medical Care (SCAMC) held in Washington, DC [22]. }\end{array}$ \\
\hline 1979 & $\begin{array}{l}\text { IMIA formally established within IFIP with separate bylaws, with Jan Roukens (the Netherlands) as IMIA President. } \\
\text { Cape Town (South Africa) Working Conference in Health Informatics Systems (HIS) forerunner of WG-10. }\end{array}$ \\
\hline 1980 & $\begin{array}{l}\text { Third MEDINFO, Tokyo [23]. David Shires (Canada) IMIA President. } \\
\text { IMIA-Latin America (LAC) regional society organized. }\end{array}$ \\
\hline 1983 & Fourth MEDINF0 83, Amsterdam [24]. Hans Peterson (Sweden) President. Nursing Informatics active. Financial crisis for IMIA. \\
\hline 1984 & American College of Medical Informatics (ACMI) established as first honorary fellowship organization in medical informatics, subsequently with international members. \\
\hline 1986 & Fifth MEDINF0, Washington, DC [25]. Shigekoto Kaihara (Japan) IMIA President. \\
\hline 1988 & IMIA becomes independent of IFIP, but maintains loose affiliation \\
\hline 1989 & $\begin{array}{l}\text { Seventh MEDINFO [26] dual venues in Beiijing and Singapore, Jos Willems (Belgium), IMIA President. } \\
\text { American Medical Informatics Association (AMIA) established by merger of precursor organizations, joins IMIA with Marion Ball as representative. }\end{array}$ \\
\hline 1992 & $\begin{array}{l}\text { Seventh MEDINF0, Geneva [27]. Marion Ball (USA) IMIA President. } \\
\text { IMIA incorporated under Swiss law - first steps to establish permanent offices and organization. } \\
\text { New regional Asia-Pacific Organization (APAMI) formed. } \\
\text { Founding of IMIA Yearbook of Medical Informatics, Jan van Bemmel (the Netherlands) and Alexa McCray (USA), Editors. Schattauer, Stuttgart, Publishers. [6] }\end{array}$ \\
\hline 1993 & HELINA: African region formed \\
\hline 1995 & Eighth MEDINF0, Vancouver [28]. Otto Rienhoff (Germany), IMIA President. \\
\hline 1997 & Steven Huesing (Canada) appointed first Executive Director for IMIA. \\
\hline 1998 & Ninth MEDINFO, Seoul [29]. Jan van Bemmel (the Netherlands), IMIA President. Affiliation with International Federation of Health Records Organization (IFHRO). \\
\hline 2001 & Tenth MEDINFO [30], London. K.C. Lun (Singapore), IMIA President. \\
\hline 2004 & Eleventh MEDINF0, San Francisco [31]. Nancy Lorenzi (USA), IMIA President. \\
\hline 2006 & IMIA Yearbook goes online and becomes supplement to Methods of Information in Medicine, also published by Schattauer.[32] \\
\hline 2007 & Twelfth MEDINF0 [33], Brisbane. Reinhold Haux (Germany), IMIA President. \\
\hline
\end{tabular}




\section{World Congresses of Medical Informatics (MEDINFOs): An Evolving International Profile of IMIA Contributions}

The World Congresses of Medical Informatics (MEDINFOs) have been the defining events of IMIA since its inception. As a triennial event it brings together all officers of the IMIA Board with the Executive Director and the national and regional representatives of the constituent societies in the General Assembly of IMIA. This group votes on all organizational matters and elects the slate of officers for the next three years. The Working Groups of IMIA meet at MEDINFO and have a chance to coordinate and bring up to date the activities of their subspecialties on an international basis. The scientific conference itself, as recorded in its proceedings, provides a snapshot of contributions from medical informatics researchers. Hence, analyzing changes in the distribution of topics over the years provides a longitudinal record of highlights of international contributions to the field. In what follows I summarize the evolution of subjects or topics for the papers and contributions from selected MEDINFO Proceedings from 1980 onwards, when IMIA was established independently from IFIP.

Categorization of papers according to the original Congress and Proceedings varies by year, so did not provide a good basis for comparison. An observation made in an editorial about the field during the regional conference for Europe's MIE 96 over a decade ago still holds today: "It was amazing that we could find little reuse of the topics from the previous MIE and MEDINFO Congresses, indicating medical informatics is a discipline in change" [34]. Since this continues to be the case, I have used the subject headings of the 2006 IMIA Yearbook of Medical Informatics to group subjects [32] in summarizing the technical and scientific subfields of the discipline. More detailed topic listings such as found in the IMIA Scientific Map [35] makes retrospective fitting into categories even more difficult, and not necessarily more accurate given the evolution of subjects and the field as a whole. On the other hand, the decisions for inclusion into today's IMIA Yearbook categories, are by necessity also only approximate, even for a Yearbook editor. A disadvantage of this approach is that professionally oriented subjects, like nursing or primary care informatics do not appear explicitly in the listings, but are subsumed under categories like HIS or Health \& Clinical Management or Education, depending on the specific sections of a particular MEDINFO and their style of categorization. Even so, the hope is that what follows may be useful for chronicling changes in subject area representation for the MEDINFO papers over the past 25 years.

Table 2 below lists the results of categorizing full paper presentations (invited and competitively selected, but not abstracts or posters) according to subject categories corresponding to those of the 2006 IMIA Yearbook [32] as indicated in the top row.

\#1. Health \& Clinical Management includes planning and evaluation, assessment, organizational change, disease management and public health as well as the specific topics of its title.

\#2. Patient records include both medical, nursing records, and databases of records as well as telemedicine applications related to records.

\#3. Health Information Systems includes a wide range of health-related systems, including nursing and various medical specialty systems.
\#4. Sensor, Signal and Imaging Informatics includes all measurement oriented analyses and systems.

\#5. Decision Support, Knowledge Representation and Management includes a broad range of medical decision making papers, text mining as well as natural language and the foundational work on terminologies, nomenclatures, ontologies, their software and how these are managed within systems.

\#6. Educational and Consumer Informatics includes papers on these topics only.

\#7. Bioinformatics includes all genomics, proteomics and other emerging omics papers.

I have used data covering the MEDINFOs from 1980 to 2004, but excluded those of 1989 and 1995, which required last minute changes of venue and organization, and are therefore atypical of the series.

MEDINFO 80 [23] was held in Tokyo from September 29 to October 4, 1980, with Morris F. Collen (USA) as chair of the Scientific Program Committee, Masamitsu Oshima (Japan) as chair of the Organizing Committee, and Donald A.B. Lindberg (USA) and Shigekoto Kaihara (Japan) as Proceedings Editors. The conference featured 28 sessions covering a diversity of topics ranging from Computers in Radiation Therapy through Hospital Care, Nursing, Care Plans, Medical Information Systems, to Pharmacy, Drug Information Systems, Registries, Epidemiology, Biostatistics, and Language, Linguistics, Text Processing, Nomenclature, and Artificial Intelligence. International participation was outstanding, and there were a total of 365 contributions, of which 279 were presented as regular papers and the remainder by abstract or poster. A. Cormack provided a contribution on "Early CAT Scanning and Recent Developments", describing some of the work which led to his Nobel Prize. 
Table 2 MEDINFO Full Papers Presented by Subject Areas (\% Total/Year): 1980-2004. All numbers in the table are percentages of the totals for the year.

\begin{tabular}{|c|c|c|c|c|c|c|c|}
\hline $\begin{array}{l}\text { Year } \\
\text { (\# of } \\
\text { papers) }\end{array}$ & $\begin{array}{l}1 . \\
\text { Health \& } \\
\text { Clinical } \\
\text { Management }\end{array}$ & $\begin{array}{l}2 . \\
\text { Patient } \\
\text { Records }\end{array}$ & $\begin{array}{l}3 . \\
\text { Health } \\
\text { Information } \\
\text { Systems }\end{array}$ & $\begin{array}{l}4 . \\
\text { Sensor, } \\
\text { Signal \& } \\
\text { Imaging } \\
\text { Informatics }\end{array}$ & $\begin{array}{l}5 . \\
\text { Decision Support, } \\
\text { Knowledge } \\
\text { Representation \& } \\
\text { Management }\end{array}$ & $\begin{array}{l}6 . \\
\text { Educational } \\
\text { \& Consumer } \\
\text { Informatics }\end{array}$ & $\begin{array}{l}7 . \\
\text { Bio- } \\
\text { informatics }\end{array}$ \\
\hline $\begin{array}{l}1980 \\
(279)\end{array}$ & 18 & 8 & 14 & 28 & 28 & 4 & NA \\
\hline $\begin{array}{l}1983 \\
(318)\end{array}$ & 12 & 7 & 29 & 21 & 23 & 8 & NA \\
\hline $\begin{array}{l}1986 \\
(275)\end{array}$ & 8 & 7 & 30 & 15 & 28 & 12 & NA \\
\hline $\begin{array}{l}1992 \\
(256)\end{array}$ & 14 & 11 & 19 & 16 & 30 & 10 & NA \\
\hline $\begin{array}{l}1998 \\
(263)\end{array}$ & 7 & 23 & 18 & 10 & 23 & 15 & 4 \\
\hline $\begin{array}{l}2001 \\
(281)\end{array}$ & 21 & 16 & 6 & 4 & 39 & 11 & 3 \\
\hline $\begin{array}{l}2004 \\
(302)\end{array}$ & 25 & 15 & 8 & 2 & 35 & 10 & 5 \\
\hline
\end{tabular}

Workshops were held in the evenings, and provided a focus for working group activities on specialized topics. While Health \& Clinical Management topics are reasonably well represented with $18 \%$ of full papers, and Health Information Systems with $14 \%$, the major contributions in 1980 were in the areas of Signal and Image processing (28\%) and Decision Support, Knowledge Representation, and Management (also $28 \%$ ). Papers in the categories of patient records and education categories lag far behind with $8 \%$ and $4 \%$, respectively, probably reflecting the immaturity of medical records technologies, and the early organizational stage of the field, respectively.

MEDINFO 83 [24] was held in Amsterdam and was organized into four tracks of 8 sessions each, with a more systematic breakdown into categories involving 1 ) health care systems, 2) underlying technologies of imaging and clinical decision making (this was the era of expert systems), 3) patient data and clinical systems, and 4) a variety of topics from education to networking, privacy and epidemiology, statistics, preventive and occupational care. The Proceedings were edited by Jan $H$. van Bemmel (the Netherlands), Marion Ball (USA), and Ove Wigertz (Sweden). G.S. Lodwick (USA) was Chair of the Program Committee, and Jan Roukens (the Netherlands) was Chair of the Organizing Committee. The keynote address was given by Lee Lusted, who had written one of the most influential books on medical decision-making in the 1960's [13] after co-authoring the seminal paper in the field with Robert Ledley [10].There is a noticeable leap in papers related to health information systems from the meeting three years earlier, doubling from $14 \%$ to $29 \%$ of total papers, possibly reflecting the rapid introduction of more flexible software, coupled with the dropping costs of mainframe computers and the introduction of microcomputers. Decision sup- port and knowledge representation papers remain high at $23 \%$, while education papers have doubled to $8 \%$. Signal and imaging papers decline to $21 \%$, beginning a continuous drop in participation in MEDINFOs which continues to the present day. Patient records papers remained about the same in number ( $7 \%$ of total) while those on health and clinical management dropped to $12 \%$ from the $18 \%$ of total papers in 1980.

MEDINFO 86 [25], held in Washington, DC, saw a further systematization and tightening of the paper selection process. Donald A. B. Lindberg (USA) was Chairman of the Organizing Committee, having become Director of the National Library of Medicine of the $\mathrm{NIH}$ just two years earlier leading it to become the major national agency for sponsoring research in medical informatics. Jan van Bemmel (the Netherlands) and Edward (Ted) H. Shortliffe (USA) headed the Scientific Program Committee and in the preface to the Proceedings [25, p. viii] give a comparative summary of attendance at all MEDINFOs up to and including theirs, showing the dramatic effect of geographical location on percentage of attendance from different regions in the world, though with a more consistent European attendance than of any other region coming to all meetings. The Proceedings were edited by R. Salamon (France), B. Blum (USA), and M. Jørgensen (Denmark). The paper distribution shows an increase in the education category to $12 \%$ of all papers as it now included decision support assisting in education through the widespread availability of PCs, and continuing decrease in signals and imaging contributions (to 15\%) and health and clinical management (to 8\%). Proportions of papers in the other areas remained approximately the same as at the Amsterdam Congress. 
Both MEDINFO 89 [26] and MEDINFO 95 [28] underwent changes in location and organization at the last moment, described in the Past Presidential retrospectives paper [10] in detail by former Presidents Kaihara and Ball. Contributions were significantly affected by these events, so they have not been included in the table and analysis.

MEDINFO 92 [27] was held in Geneva, where Jean-Raoul Scherrer headed the Organizing Committee, while the Program Committee was headed by Salah Mandil (WHO), and the Proceedings edited by KC Lun (Singapore), Patrice Degoulet (France), Tom Piemme (USA) and Otto Rienhoff (Germany). The major changes in distribution of papers by categories was a notable increase in those for Health and Clinical Management (to $14 \%$ ), as well as in the Patient Records group (11\%), which was offset by a corresponding decrease in Health Information Systems (to 19\% from the previous $30 \%$ ). This possibly reflects the increased maturity of systems in these fields, which were now more ready to be used for clinical management, human factors studies, and evaluation. Signals and Imaging remained about the same $(16 \%)$ as did Decision Support and Knowledge Representation and Management (30\%), while Education papers dipped slightly to $10 \%$ of the total.

MEDINFO 98 [29], convened in Seoul. The Scientific Program Committee was headed by Charles Safran (USA) and Patrice Degoulet (France), and the Chairs of the Editorial Committee were Branko Cesnik (Australia), Alexa T. McCray (USA) and Jean-Raoul Scherrer (Switzerland). The Organizing Committee Chair was Chang Soon Koh (Korea). There was a new category of Bioinformatics papers presented for the first time (at $4 \%$ of papers), and a great increase in the number of papers related to Patient Records (23\%) and
Educational and Consumer Informatics $(15 \%)$ compared to earlier meetings, with decreases in Health and Clinical Management (to 7\%), Signal and Imaging (10\%), and even Decision Support, Knowledge Representation and Management (23\% down from the previous $30 \%)$.

MEDINFO 01 [30] held in London, had its SPC chaired by Arie Hassman (the Netherlands) and Hiroshi Takeda (Japan), its Organizing Committee by Jean Roberts (U.K), and its editorial Committee was headed by Vimla Patel (USA). Health \& Clinical Management papers $(21 \%)$ now were more balanced with those in Patient records (16\%) than in 1998, while those in HIS $(6 \%)$ decreased in numbers. Signals and Imaging dropped precipitously (to $4 \%$ of total) while Decision Support and Knowledge Representation and Management increased considerably to $39 \%$, with Education and Consumer Health remaining about the same (10\%), as did Bioinformatics ( $3 \%$ of total).

MEDINFO 04 [31] met in San Francisco, with its Scientific Program Committee headed by Mario Stefanelli (Italy) and Casimir Kulikowski (USA), its Organizing Committee was headed by Ted Shortliffe (USA), and its editorial Committee by Marius Fieschi (France), Enrico Coeira (Australia) and Yu-Chan Jack Li (Taiwan). Decision Support, Knowledge Representation and Management was again highly represented (35\% of total papers), with Health and Clinical Management growing considerably (to $25 \%$ ), and Patient records also high (15\%). Signals and Imaging almost disappear ( $2 \%$, with a single session), while Education (11\%), Patient Records (15\%), and HIS( $8 \%$ ) remained stable in relative numbers.

Overall, between the 1980 and 2004 MEDINFOs we can see that the combined first three categories of Health and Clinical Management, Patient
Records and Health Information Systems account fairly consistently for between $40 \%$ and $48 \%$ of the total papers accepted for full presentation, despite considerable fluctuations in the percentage of papers in each individual category, which seems to depend partly on technology trends and partly on subject classification criteria. Similarly, the very broad category of Decision Support, Knowledge Representation and Management ranges consistently between $28 \%$ and $39 \%$ of papers submitted. Meanwhile, papers in Signals and Imaging (and Sensors more recently) have dropped considerably from $28 \%$ of all papers presented in 1980 to just $2 \%$ in 2004 , possibly reflecting the increasing technical specialization of these fields and the fact that researchers will present their best work for peer review at the most specific relevant conference. Medical Informatics Educational papers have accounted for about $10 \%$ to $15 \%$ of papers since 1986 , and Bioinformatics, a new category since 1998 , accounts for only $5 \%$ of papers, again probably reflecting the fact that specialized conferences will attract most of the top papers in this field, and participation in MEDINFO is only likely for authors committed to the healthrelated aspects of their research and members of the medical informatics community.

One might conclude from the above that biomedical and health informatics has evolved in such a way that it is now organized around two major clusters of subjects: the first related to the practical systems, records, and management issues involved in health care, and the second related to the foundational issues of knowledge representation and management, and decision support within biomedical and health informatics systems. Health informatics education is important but not preponderantly represented, and the specialized 
scientific and technological subfields have become minimally represented within the broader field.

The distribution of full and invited papers at MEDINFOs by geographical IMIA region (as defined by its constituent society groupings in 2006), is given above in Table 3. It can be seen that both Europe and North America have contributed the largest percentage of full papers presented when the MEDINFO was in their region. On the other hand, Asia-Pacific has typically contributed less than Europe when the MEDINFO was held in Asia (again, without considering the unusual Beijing/Singapore dual venue of 1980). Overall, between 1980 and 2004, Europe has contributed and presented more full papers at MEDINFOs, followed by North America and Asia, with minimal representation from Latin America and Africa. This most likely represents the "founder effect" of IMIA having first coalesced in Europe, together with other factors such as differential travel costs to distant venues, competing local conferences in health and biomedical informatics in some regions in a given MEDINFO year, real or perceived values and rewards for participating in an international meeting like MEDINFO for different groups of professionals, and the distribution of strengths in research, practice, and education across the regions worldwide. It is difficult to assess the contributions of these factors retrospectively as they differ so much from year to year, and depend very much on the particular circumstances surrounding the conferences as well as more general trends in the field. However, this would make an interesting topic for a prospective study of IMIA in the future.

MEDINFO 2007 [33] being held in Brisbane, marks a new era in bringing IMIA's major conference to the Southern Hemisphere, with a strong empha-

Table 3 MEDINFO Full Papers Presented by World Regions. All numbers in the table are percentages of the totals for the year. $A^{*}$ indicates the region with largest contribution of full/invited papers in a given year.

\begin{tabular}{llllll}
$\begin{array}{l}\text { MEDINF0 } \\
\text { Year/Venue } \\
\text { (\# of papers) }\end{array}$ & Europe & North America & Asia Pacific & Latin America & Africa \\
\hline $\begin{array}{l}1980 \text { Tokyo } \\
(279)\end{array}$ & $47^{*}$ & 16 & 35 & 1 & 1 \\
$\begin{array}{l}1983 \text { Amsterdam } \\
(318)\end{array}$ & $67^{*}$ & 23 & 13 & 1 & 1 \\
$\begin{array}{l}1986 \text { Washington, DC } \\
(275)\end{array}$ & 40 & $50^{*}$ & 7 & 3 & $<1$ \\
$\begin{array}{l}1992 \text { Geneva } \\
(256)\end{array}$ & $52^{*}$ & 32 & 13 & 2 & 1 \\
$\begin{array}{l}1998 \text { Seoul } \\
(263)\end{array}$ & $46^{*}$ & 27 & 25 & 1 & 1 \\
2001 London & $54^{*}$ & 28 & 16 & 1 & 1 \\
$(281)$ & & & & & \\
2004 San Francisco & 37 & $54^{*}$ & 7 & 2 & $<1$ \\
$(302)$ & & & & & \\
\end{tabular}

sis on the breadth of health informatics, including the $1^{\text {st }}$ World Nursing Informatics Leadership Conference. The selection of Cape Town by the IMIA General Assembly for the 2010 MEDINFO will reinforce the regional diversification by highlighting the role of contributions of informatics to medicine and health in Africa, a continent which faces some of the most acute health challenges in the world.

\section{IMIA Working Groups: International Coalescence of Practice in Health Informatics}

As noted earlier, the four working groups of IFIP's TC-4 preceded the formation of IMIA itself, and led to the first international professional activities devoted to specific research fields in medical informatics. Table 1 lists a number of early working group conferences sponsored by the IFIP TC-4. The international range of contributions to different subjects can be gauged to some extent by the diversity of countries of origin of the leadership of the various Working Groups over the years as indicated together with the approximate year of establishment of the Working Groups indicated below.

Special Interest Group 1 - Nursing Informatics (1982) - with eight specialty working groups: the Netherlands, USA, Australia, UK, New Zealand (see [36] for details).

WG-1: Health and Medical Informatics Education (1974): France, Canada, Germany, Greece, Australia

WG-2: Consumer Health Informatics (2003): USA, Canada

WG-3: Intelligent Data Analysis and Data Mining (2004): Italy, Slovenia WG-4: Data Protection in Health Information Systems (1976): Germany, t he Netherlands, Sweden, UK WG-5: Primary Health Care Informatics (1990): UK, Australia

WG-6: Medical Concept Representation/Coding and Classification of Health Data (1983): Germany, Switzer- 
land, Canada, USA

WG-7: Biomedical Pattern Recognition (1985): the Netherlands, Germany WG-8: Mental Health (2000): UK, Ireland WG-9: Health Informatics for Development (1992): Brazil, Argentina, UK, Romania

WG-10: Health Information Systems/ Hospital Information Systems (1988): the Netherlands, USA, Germany,

WG-11: Dental Informatics (1980's): USA, Austria,

WG-12: Biomedical Statistics \& Information Processing (2002): Czech Republic, Poland

WG-13: Organizational and Social Issues (1998): USA

Former WG-14: Health Professional Workstations (1995): USA and Switzerland

WG-15: Technology Assessment and Quality Improvement (2004): the Netherlands, Denmark

WG-16: Standards In Health Care Informatics (1998): Belgium, Japan

WG-17 Electronic Patient Records (1997): the Netherlands

WG-18 Telematics in Health Care (1992): France

WG- Open Source Health Informatics (2002): UK, Czech Republic

WG- Informatics in Genomic Medicine (2002): Spain, USA.

From the above it can be seen that there is a wide geographical participation in the leadership of the IMIA working groups over the years, though with a preponderance of European and North American participants, but increasingly robust participation from the Asia-Pacific region, and Latin America.

\section{The IMIA Yearbook of Medical Informatics}

The Yearbook was founded by Jan van Bemmel, who was its first editor with
Alexa McCray starting in 1992. The original idea from Moris Collen was to publish a Yearbook for AMIA. This suggestion was widened to publish it under the umbrella of IMIA. The purpose was to provide a record of IMIA activities and research contributions through the selection and re-printing of outstanding papers in the field from the previous year (or in some cases 18 months). Each year a theme is selected to reflect current advances or emphases of research and practice in medical informatics. Tracing the selection of the themes allows for yet a different view of how medical informatics (and health and biomedical informatics more generally) has been evolving for the past 15 years. Starting in 2001, Reinhold Haux and Casimir Kulikowski became the Yearbook editors joined in 2007 by Antoine Geissbuhler.

The topics of the Yearbooks are:

1992 Advances in an Interdisciplinary

Science [6]

1993 Sharing Knowledge and Information [37]

1994 Advanced Communications in Health Care [38]

1995 The Computer-based Patient Record [39]

1996 The Integration of Information for Patient Care [40]

1997 Computing and Collaborative Care [41]

1998 Health Informatics and the Internet [42]

1999 The Promise of Medical Informatics [43]

2000 Patient-centered Systems [44]

2001 Digital Libraries and Medicine [45] 2002 Medical Imaging Informatics [46] 2003 Quality of Health Care: Informatics Foundations [47]

2004 Towards Clinical Bioinformatics [48] 2005 Ubiquitous Health Care Systems [49] 2006 Assessing Information Technologies for Health [32]

2007 Sustainable Health Care Systems [50]
2008 Access to Health Information (proposed)

As can be seen, the themes are very broad, characterizing how informatics impacts health care and research, and how it relates to its underlying scientific and technological foundations.

The geographical spread of best papers selected by the IMIA Yearbook from the medical informatics literature in the prior year or 18 months, together with original invited contributions on topics related to the themes of the yearbook and the major areas of the field, in the form of critical reviews and surveys of the literature, is listed in Table 4. It can be seen that North America contributes about $50 \%$ of the papers in most years, with Europe contributing about 40\%, the Asia-Pacific region from $4 \%$ to $9 \%$, and Latin America and Africa at most $3 \%$ annually. This distribution reflects the strength of research contributions published in the field as evaluated by an international group of referees and selected by an editorial board which has been primarily based in Europe (The Netherlands, Austria, Germany, and, from 2007, Switzerland).

In analyzing the range of proposed best papers across the world over these years one can see that a number of effects influence the outcome besides those for MEDINFO listed above. Since both proposals and selections are made from the published literature in English in the prior year to year-and-a-half, it reflects the prevalence of publications in peer-reviewed journals from various regions in a literature which is predominantly North American and $\mathrm{Eu}-$ ropean. This excludes many regional publications written in other languages, or of uncertain peer-review status, which may nevertheless contain important information on projects in medical informatics. Until such literature becomes more widely available and recognized, it is still not likely to make 
Table 4 Regional distribution of best papers selected from the prior year MI literature and invited contributed papers included in the IMIA Yearbook of Medical Informatics for selected years from its founding in 1992 to 2006. All numbers in the table are percentages of the totals for a given year.

\begin{tabular}{|llllll|}
\hline IMIA Yearbook & Europe & North America & $\begin{array}{l}\text { Asia } \\
\text { Pacific }\end{array}$ & Latin America & Africa \\
\hline 1992 & 37 & 57 & 6 & - & - \\
1994 & 38 & 58 & 4 & - & - \\
1998 & 42 & 47 & 9 & 2 & - \\
2001 & 37 & 50 & 9 & 2 & 2 \\
2004 & 52 & 39 & 7 & $<1$ & $<1$ \\
2006 & 39 & 53 & 8 & - & - \\
2007 & 36 & 47 & 14 & - & 3 \\
\hline
\end{tabular}

a strong international impact, but with the rapid dissemination of web-based information it raises important challenges for the future IMIA Yearbook to consider in terms of mechanisms of editorial selection and inclusion to broaden the geographical representation of medical and health informatics work of high quality across the globe.

\section{The IMIA Code of Ethics}

An important role of IMIA is to provide worldwide guidelines for practitioners of health informatics in dealing with complex ethical situations which may arise at the intersection of informatics and health care. The IMIA Code of Ethics for Health Information Professionals was endorsed at its General Assembly meeting in 2004 and is the result of years of global collaboration led by IMIA's working Group on Data Protection in Health Information, chaired by Ab Bakker of the Netherlands. The main author of the code, based on the contributions of many individuals, agencies and organizations, is Dr. Eike-Henner W. Kluge, Professor, Department of Philosophy, University of Victoria, Victoria, BC, Canada. In addition to the code itself, there is a detailed handbook of explanations that

\section{Conclusion}

IMIA's roots in IFIP's TC-4 and the development of a separate identity as IMIA proper by the late 1970 's, helped define medical informatics while giving the field an international professional dimension from the beginning. The foresight of the founders to see the advantages of coalescing the very divergent strands of the field so early, before most national societies were even formed, has helped make IMIA what it is today: the premier world organization that brings together researchers, practitioners, and educators to debate their approaches, discern the major challenges and encourage new directions for the future of the field.

The IMIA Code of Ethics for Health Information Professionals is available in many languages: Chinese, Croatian, Czech, Dutch, English, French, German, Japanese, Korean, Portuguese, Russian, and Spanish with a number more planned.

Dr. Kluge has authored a related Handbook of Ethics for Health Informatics Professionals, published by the British Computer Society (2003), and available in PDF format in English only at [51] .The IMIA Code of Ethics and the accompanying set of Rules of Ethical Conduct do not make reference to such things as technical standards of secure data communication, or to provisions that are necessary to ensure a high quality of handling, collecting, storing, transmitting and manipulating health care data. This is deliberate - the authors considered that while the development and implementation of technical standards has ethical dimensions, and while these dimensions are reflected in the Code and the Rules as ethical duties, the details of such technical standards are not themselves a matter of ethics (excerpted and paraphrased from the website of imia.org's section on the Code of Ethics [51]).

\section{Acknowledgement}

The author wishes to thank Jan van Bemmel, Antoine Geissbuhler, Reinhold Haux and Steven Huesing for their many helpful suggestions on this paper, and to Joyce Mitchell for suggesting an analysis of MEDINFO contributions.

\section{References}

1. IMIA's History: website:http:///www.imia.org/ history.html

2. Degoulet P, Haux R, Kulikowski C, Lun KC. François Grémy and the birth of IMIA. 1 $^{\text {st }}$ IMIA/ UMIT Medical Informatics Award of Excellence given to Professor Grémy, Methods Inf Med 2005; 44(3):349-51.

3. van Bemmel JH, Bergemann D. Gustav Wagner (1918 - 2006) Founding Editor of Methods: In Memoriam. Methods Inf Med 2007;46(1):1.

4. Peterson HE. From Punched Cards to Computerized Patient Records: A Personal Journey. In: Haux R, Kulikowski CA, editors. IMIA Yearbook of Medical Informatics 2006. Stuttgart: Schattauer; 2006. p. 174-79.

5. Anderson J, Forsyth JM. MEDINFO 74, Amsterdam: North Holland; 1974.

6. van Bemmel JH, McCray AT, editors. 1992 Yearbook of Medical Informatics: Advances in an Inter-

7. http:///www.imia.org/

8. Collen MF. A History of Medical Informatics in the United States: 1950 to 1990. American Informatics Association; 1995.

9. Blum R; Duncan K. A History of Medical Informatics. ACM Press; 1990.

10. Ledley RS, Lusted LB. Reasoning Foundations of Medical Diagnosis. Science 1959;130(3366):9-21. disciplinary Science. Stuttgart: Schattauer; 1992. 
11. Ball MJ, van Bemmel JH, Kaihara S. IMIA Presidential Retrospectives on Medical Informatics. In: Geissbuhler A, Haux R, Kulikowski CA, editors. 2007 IMIA Yearbook of Medical Informatics. Stuttgart: Schattauer; 2007. Methods Inf Med 2007; 46 Suppl 1:165-75.

12. Lindberg DAB. The Computer and Medical Care. Springfield: Thomas; 1968

13. Lusted LB. Introduction to Medical Decision Making, Springfiled: Thomas; 1968.

14. Anderson J, Forsythe JM, editors. Information Processing of Medical Records. Amsterdam: North Holland; 1970.

15. Zywietz C, Schneider B, editors. Computer Application on ECG and VCG Analyses. Amsterdam: North Holland; 1973.

16. Moehr JR. History of Medical Informatics; English Translation of the Minutes of the Invitational Workshop Goals, Contents and Methods for Education in Medical Informatics. In: Haux R, Kulikowski CA, editors. 2004 Yearbook of Medical Informatics. Stuttgart: Schattauer; 2004. p 210-16.

17. Anderson J, Forsythe JM, editors. MEDINFO 74. Amsterdam: North-Holland; 1974

18. Anderson J, Gremy F, Pages JC, editors. Education in Informatics of Health Personnel. Amsterdam: North Holland; 1974.

19. Bailey NTJ, Aendov B, Tsanev R, editors. Mathematical Models in Biology and Medicine. Amsterdam: North Holland; 1974.

20. Lindberg DAB Reichertz PL Reinhoff O (eds) Lecture Notes on Medical Informatics. Heidelberg and New York: Springer Verlag, 1974 - 1991.

21. Shires DB, Wolf H, editors. MEDINFO 77. Amsterdam: North-Holland; 1977.

22. Proceedings The First Annual Symposium on Computer Application in Medical Care, Long Beach: IEEE Computer Society, 1977.

23. Lindberg DAB, Kaihara S, editors. MEDINFO 80. Amsterdam: North-Holland; 1980

24. van Bemmel JH, Ball MJ, Wigertz O, editors.
MEDINFO 83 Amsterdam: North-Holland; 1983.

25. Salamon R, Blum B, Jørgensen M, editors. MEDINFO 86. Amsterdam: North-Holland; 1986.

26. Barber B, Cao D, Qin D, Wagner G, editors. MEDINFO 89. Amsterdam: North-Holland; 1989.

27. Lun KC, Degoulet P, Piemme TE, Rienhoff O, editors. MEDINFO 92. Amsterdam: North-Holland; 1992.

28. Greenes RA, Peterson HE, Protti DJ, editors. MEDINFO 95. Amsterdam: North-Holland; 1995.

29. Cesnik B, McCray AT, Scherrer J-R, editors. MEDINFO 98. Amsterdam: IOS Press; 1998.

30. Patel V, Rogers R, Haux R, editors. MEDINFO 01. Amsterdam: IOS Press; 2001

31. Fieschi M, Coiera E, LI Y-C, editors. MEDINFO 04. Amsterdam: IOS Press; 2004

32. Haux R, Kulikowski C, editors. 2006 IMIA Yearbook of Medical Informatics: Assessing Information Technologies for Health. Methods Inf Med 45 Suppl. 1.

33. Kuhn KA, Leong T-Y, Warren J. MEDINFO 07. Amsterdam: IOS Press. In press 2007.

34. Brender J Scherrer JR Christensen JP McNair P Editorial, Proceedings MIE 96.

35. IMIA Recommendations of the International Medical Informatics Association (IMIA) on Education in Health and Medical Informatics. Methods Inf Med 2000;39;267-77.

36. http://www.imia.org/ni/index.html

37. van Bemmel JH, McCray AT, editors. 1993 Yearbook of Medical Informatics: Sharing Knowledge and Information. Stuttgart: Schattauer; 1993.

38. van Bemmel JH, McCray AT, editors. 1994 Yearbook of Medical Informatics: Advanced Communications in Health Care. Stuttgart: Schattauer; 1994.

39. van Bemmel JH, McCray AT, editors. 1995 Yearbook of Medical Informatics: The Computer-based Patient Record. Stuttgart: Schattauer; 1995.

40. van Bemmel JH, McCray AT, editors. 1996 Yearbook of Medical Informatics: The Integration of Information for Patient Care. Stuttgart: Schattauer; 1996.
41. van Bemmel JH, McCray AT, editors. 1997 Yearbook of Medical Informatics: Computing and Collaborative Care. Stuttgart: Schattauer; 1997.

42. van Bemmel JH, McCray AT, editors.1998 Yearbook of Medical Informatics: Health Informatics and the Internet. Stuttgart: Schattauer; 1998.

43. van Bemmel JH, McCray AT, editors. 1999 Yearbook of Medical Informatics: The Promise of Medical Informatics. Stuttgart: Schattauer; 1999.

44. van Bemmel JH, McCray AT, editors. 2000 Yearbook of Medical Informatics: Patient-centered Systems. Stuttgart: Schattauer; 2000

45. Haux R, Kulikowski C, editors. 2001 Yearbook of Medical Informatics: Digital Libraries and Medicine. Stuttgart: Schattauer; 2001.

46. Haux R, Kulikowski C, editors. 2002 Yearbook of Medical Informatics: Medical Imaging Informatics. Stuttgart: Schattauer; 2002.

47. Haux R, Kulikowski C, editors. 2003 Yearbook of Medical Informatics: Quality of Health Care: Informatics Foundations. Stuttgart: Schattauer; 2003

48. Haux R, Kulikowski C, editors. 2004 Yearbook of Medical Informatics: Towards Clinical Bioinformatics. Stuttgart: Schattauer; 2004.

49. Haux R, Kulikowski C, editors. 2005 Yearbook of Medical Informatics: Ubiquitous Health Care Systems. Stuttgart: Schattauer; 2005.

50. Geissbuhler A, Haux R, Kulikowski C, editors, 2007 Yearbook of Medical Informatics: Sustainable Health Care Systems. Stuttgart: Schattauer; 2007. 51. www.health-informatics.org/ethicsmain.pdf

\section{Correspondence to:}

Casimir A. Kulikowski

Department of Computer Science

Hill Center, Busch Campus

Rutgers University

New Brunswick, New Jersey 08901, USA

E-mail: kulikows@cs.rutgers.edu 